\title{
Voriconazole greatly increases the exposure to oral buprenorphine
}

\section{Fihlman, Mari}

2018-12

Fihlman , M , Hemmilä , T , Hagelberg , N M , Backman , J T, Laitila , J , Laine , K, Neuvonen, P J , Olkkola , K T \& Saari , T I 2018, ' Voriconazole greatly increases the exposure to oral buprenorphine ' , European Journal of Clinical Pharmacology , vol. 74 , no. 12 , pp. 1615-1622 . https://doi.org/10.1007/s00228-018-2548-8

http://hdl.handle.net/10138/268045

https://doi.org/10.1007/s00228-018-2548-8

publishedVersion

Downloaded from Helda, University of Helsinki institutional repository.

This is an electronic reprint of the original article.

This reprint may differ from the original in pagination and typographic detail.

Please cite the original version. 


\title{
Voriconazole greatly increases the exposure to oral buprenorphine
}

\author{
Mari Fihlman ${ }^{1,2} \cdot$ Tuija Hemmilä $^{2} \cdot$ Nora M. Hagelberg ${ }^{1,2} \cdot$ Janne T. Backman $^{3} \cdot$ Jouko Laitila $^{3} \cdot$ Kari Laine $^{4,5}$. \\ Pertti J Neuvonen ${ }^{3} \cdot$ Klaus T. Olkkola $^{6} \cdot$ Teijo I. Saari $^{1,2}$
}

Received: 22 June 2018 / Accepted: 22 August 2018 / Published online: 30 August 2018

(C) Springer-Verlag GmbH Germany, part of Springer Nature 2018

\begin{abstract}
Purpose Buprenorphine has low oral bioavailability. Regardless of sublingual administration, a notable part of buprenorphine is exposed to extensive first-pass metabolism by the cytochrome P450 (CYP) 3A4. As drug interaction studies with buprenorphine are limited, we wanted to investigate the effect of voriconazole, a strong CYP3A4 inhibitor, on the pharmacokinetics and pharmacodynamics of oral buprenorphine.

Methods Twelve healthy volunteers were given either placebo or voriconazole (orally, $400 \mathrm{mg}$ twice on day 1 and $200 \mathrm{mg}$ twice on days 2-5) for 5 days in a randomized, cross-over study. On day 5, they ingested $0.2 \mathrm{mg}(3.6 \mathrm{mg}$ during placebo phase) oral buprenorphine. We measured plasma and urine concentrations of buprenorphine and norbuprenorphine and monitored their pharmacological effects. Pharmacokinetic parameters were normalized for a buprenorphine dose of $1.0 \mathrm{mg}$.

Results Voriconazole greatly increased the mean area under the plasma concentration-time curve $\left(\mathrm{AUC}_{0-18}\right)$ of buprenorphine (4.3-fold, $P<0.001)$, its peak concentration $\left(C_{\mathrm{max}}\right)\left(3.9\right.$-fold), half-life $(P<0.05)$, and excretion into urine $\left(A_{\mathrm{e}} ; P<0.001\right)$. Voriconazole also markedly enhanced the $C_{\max }(P<0.001), \mathrm{AUC}_{0-18}(P<0.001)$, and $A_{\mathrm{e}}(P<0.05)$ of unconjugated norbuprenorphine but decreased its renal clearance $(P<0.001)$. Mild dizziness and nausea occurred during both study phases. Conclusions Voriconazole greatly increases exposure to oral buprenorphine, mainly by inhibiting intestinal and liver CYP3A4. Effect on some transporters may explain elevated norbuprenorphine concentrations. Although oral buprenorphine is not commonly used, this interaction may become relevant in patients receiving sublingual buprenorphine together with voriconazole or other CYP3A4 or transporter inhibitors.
\end{abstract}

Keywords Buprenorphine - Norbuprenorphine - Voriconazole Pharmacokinetics · Drug-drug interaction · CYP3A4 . Transporters

Electronic supplementary material The online version of this article (https://doi.org/10.1007/s00228-018-2548-8) contains supplementary material, which is available to authorized users.

Teijo I. Saari

teisaa@utu.fi

1 Department of Anaesthesiology and Intensive Care, University of Turku, P.O. Box 52, Kiinamyllynkatu 4-8, FI-20520 Turku, Finland

2 Division of Perioperative Services, Intensive Care and Pain Medicine, Turku University Hospital, Turku, Finland

3 Department of Clinical Pharmacology, University of Helsinki and Helsinki University Hospital, Helsinki, Finland

4 Department of Pharmacology, Drug Development and Therapeutics, University of Turku, Turku, Finland

5 Medbase Ltd., Turku, Finland

6 Department of Anaesthesiology, Intensive Care and Pain Medicine, University of Helsinki and Helsinki University Hospital, Helsinki, Finland

\section{Introduction}

Buprenorphine is a partial $\mu$-opioid receptor agonist, which antagonizes $\mathrm{K}$-opioid receptor and acts as an agonist at the $\delta$-opioid receptor and opioid receptor-like receptor $[1,2]$. Buprenorphine is increasingly used for treating acute and chronic pain. Analgesic doses range from 0.3 to $0.6 \mathrm{mg}$ when intravenous or intramuscular dosing routes are used. Buprenorphine is also a good option for substitution therapy to treat opioid dependence because of its pharmacokinetic and pharmacodynamic properties. Buprenorphine produces long-lasting subjective and physiologic effects without significant respiratory depression $[3,4]$. Sublingual doses used in opioid substitution therapy are much higher than those used in treatment of chronic pain, but buprenorphine is considered to be safe because of its ceiling effects [4]. 
Buprenorphine has very low oral bioavailability because of its extensive first-pass metabolism $[5,6]$. The bioavailability is higher, about $15-30 \%$, when buprenorphine is administered sublingually [7, 8]. The mean time to maximum plasma concentration following sublingual administration varies from 1 to $3 \mathrm{~h}$ [9-12]. After an oral and sublingual buprenorphine administration, extensive first-pass metabolism and large interindividual variability increase the susceptibility to drug interactions. Furthermore, many opioids are substrates to some transporter proteins, such as P-glycoprotein, which can affect their absorption and systemic clearance [13-15].

The main metabolic pathway $(65 \%)$ of buprenorphine is cytochrome P450 (CYP) 3A4/5-mediated Ndealkylation of the drug, which yields an active metabolite, norbuprenorphine. CYP2C8 and CYP2C9 have been also shown to metabolize buprenorphine [16-19]. Buprenorphine and norbuprenorphine are conjugated to their 3-glucuronides mainly by the UDP-glucuronosyl transferases (UGT) $2 \mathrm{~B} 7$ and $1 \mathrm{~A} 1$, and $1 \mathrm{~A} 3$ and $1 \mathrm{~A} 1$, respectively [5, 20, 21]. Previous study with $63 \mathrm{Ni}$ electroncapture gas chromatographic assay evaluated the levels buprenorphine and its metabolites in human urine and feces [22], and approximately $10-30 \%$ of the dose was excreted in urine, mainly as conjugated metabolites. Similar results have been published, showing that $15 \%$ of conjugated metabolites are excreted in urine [5], and only small amounts of unconjugated parent drug or norbuprenorphine are excreted into urine; most of the dose is eliminated in the feces [5, 23].

The effect of strong CYP3A4 inhibitors on the pharmacokinetics of buprenorphine is largely unknown, particularly after its oral ingestion. A previous study showed that ketoconazole does not have clinically significant interactions with transdermally delivered buprenorphine [24]. Other interaction studies have been conducted with patients receiving simultaneous buprenorphine substitution and antiretroviral therapy [25]. Voriconazole is frequently used in immunosuppressed patients with suspected aspergillosis. Voriconazole is a potent inhibitor of CYP3A4, CYP2B6, CYP2C9, and CYP2C19 enzymes [26-28]. Oral buprenorphine is not commonly used in clinical settings, but very large doses of sublingual buprenorphine from 16 to $32 \mathrm{mg}$ are administered in substitution therapy $[29,30]$. A considerable part of the sublingual dose can be swallowed, making buprenorphine susceptible to first-pass metabolism in the gut wall and liver [7, 31]. Here, we wanted to study the pharmacokinetics of oral buprenorphine after its immediate swallowing, with or without voriconazole, to evaluate the magnitude of interaction after their possible concomitant ingestion.

\section{Materials and methods}

\section{Study participants}

In view of our previous studies [12, 32], it was calculated that ten subjects would be needed to detect a $30 \%$ difference in the area under the plasma concentration-time curve $\left(\mathrm{AUC}_{0-\infty}\right)$ of buprenorphine at a power of $80 \%$ and level of significance of $P<0.05$. To also consider potential dropouts, we recruited 12 healthy non-smoking volunteers (4 females and 8 men; age range 18 to 29 years; body mass index from 20.5 to $27.8 \mathrm{~kg} /$ $\mathrm{m}^{2}$ ). E-mail announcements, assigned to university students, were used to recruit participants. A written informed consent was obtained. The criteria for exclusion included concomitant drug therapy, previous history of intolerance to any of the drugs studied, past history of significant disease, alcoholism, drug abuse or psychological or emotional problems, blood donation within 4 weeks prior to study, and participation in any other studies involving drug products within 1 month prior to this study. Female participants were given instructions to use safe non-hormonal contraception during the study because hormonal contraceptives were not allowed. Clinical examination and routine laboratory tests were performed to evaluate participants' physical health. Their medical history was also evaluated, and all 12 participants were found to be in good physical health. Urine toxicology and pregnancy tests were negative and ECGs were in normal limits. The Finnish translation of the Abuse Questions [33] was used to evaluate the risk of participants to develop opioid abuse, and the risk was found to be low for every participant. Volunteers were not allowed to consume coffee, tea, and energy drinks or grapefruit juice during the study.

\section{Study outline and drug administration}

The study protocol was approved by the ethics committee of the Hospital District of Southwest Finland and by the Finnish National Agency for Medicines and was registered in the EudraCT clinical trials register under code 2011-001939-23. The clinical phase of the study was conducted in the research facilities of the Department of Clinical Pharmacology and TYKSLab, University of Turku and Turku University Hospital, Finland. The volunteers ingested orally, in randomized order either voriconazole or placebo for 5 days. Dosing of voriconazole (Vfend $® 200 \mathrm{mg}$ tablet; Pfizer, Sandwich, Great Britain) was $400 \mathrm{mg}$ at 8.00 and 20.00 on day $1,200 \mathrm{mg}$ at 8.00 and 20.00 on days $2-4$, and $200 \mathrm{mg}$ at 10.00 and 20.00 on day 5 . The washout interval in this cross-over study was 4 weeks. On the fifth day of pretreatment, all subjects ingested a single dose of $0.2 \mathrm{mg}$ (3.6 mg during placebo phase) of oral buprenorphine (Temgesic $\AA 0.2$ tablet RB Pharmaceuticals Limited, Slough, Great Britain) with $200 \mathrm{ml}$ of water at 11.00 on empty stomach. 
Adherence with the voriconazole/placebo dosing schedule was assessed using mobile phone text messages. After taking each dose, the subjects sent a mobile phone text message to one of the investigators. The investigator contacted the subject if no text message was received within 15-20 min after scheduled dosing time and reminded them to take the dose. The volunteers fasted overnight $(8 \mathrm{~h})$ before the administration of buprenorphine. Standardized meals were served 4 and $8 \mathrm{~h}$ after buprenorphine ingestion.

\section{Blood sampling and drug analysis}

On the test days, a forearm vein was cannulated, and timed blood samples $(10 \mathrm{ml})$ for pharmacokinetic measurements were collected into ethylenediaminetetraacetic acidcontaining tubes immediately before and $0.5,1,1.5,2,3,4$, $5,6,8,10,12$, and $18 \mathrm{~h}$ after the ingestion of buprenorphine. Plasma was separated within $30 \mathrm{~min}$ and stored at $-70{ }^{\circ} \mathrm{C}$ until drug analysis. Urine was collected up to $18 \mathrm{~h}$ after buprenorphine administration. Urine aliquots were stored at $-70{ }^{\circ} \mathrm{C}$ until analysis.

The concentrations of buprenorphine and norbuprenorphine in plasma and urine samples were analyzed with a validated liquid chromatography tandem mass spectrometric method as previously described [12]. The low limit of quantification (LLQ) for plasma and urine buprenorphine was $0.02 \mathrm{ng} / \mathrm{ml}$ and for norbuprenorphine $0.05 \mathrm{ng} / \mathrm{ml}$. Concentrations below the LLQ but clearly detectable were used as LLQ/2 in calculation of the mean (SD) concentrations. The interday coefficients of variation (CV\%) were for buprenorphine $8.0 \%$ at $5.3 \mathrm{ng} / \mathrm{ml}$, $8.7 \%$ at $0.53 \mathrm{ng} / \mathrm{ml}$, and $6.1 \%$ at $0.053 \mathrm{ng} / \mathrm{ml}$ and for norbuprenorphine $3.7 \%$ at $4.8 \mathrm{ng} / \mathrm{ml}, 8.7 \%$ at $0.48 \mathrm{ng} / \mathrm{ml}$, and $11.9 \%$ at $0.048 \mathrm{ng} / \mathrm{ml}$.

Plasma concentrations of voriconazole were determined from the samples taken on day 5 before administration of buprenorphine by using liquid chromatograph equipped with Waters Symmetry C8 column (Waters) and UV detection at $255 \mathrm{~nm}$ wave length as described before [34]. Diazepam was used as the internal standard. The LLQ for voriconazole was $10 \mathrm{ng} / \mathrm{ml}$. The CVs for voriconazole were below $10 \%$ at relevant plasma concentration range, i.e., $7.5 \%$ at $4000 \mathrm{ng} / \mathrm{ml}$, $3.0 \%$ at $1100 \mathrm{ng} / \mathrm{ml}$, and $5.5 \%$ at $110 \mathrm{ng} / \mathrm{ml}$.

\section{Pharmacokinetic measurements}

The peak plasma concentrations $\left(C_{\max }\right)$ and corresponding time to $C_{\max }\left(t_{\max }\right)$ of buprenorphine and norbuprenorphine were observed directly from the data. The areas under the buprenorphine and norbuprenorphine plasma concentrationtime curves (AUC) from 0 to $18 \mathrm{~h}\left(\mathrm{AUC}_{0-18}\right)$ were calculated by non-compartmental methods using WinNonlin pharmacokinetics program (version 4.1; Pharsight, Mountain View, CA). The terminal log-linear part of each concentration-time curve was identified visually, and the elimination rate constant $\left(k_{\mathrm{e}}\right)$ was calculated from the logarithmically transformed data using linear regression analysis. The $t_{1 / 2}$ was calculated using the equation $t_{1 / 2}=\ln 2 / k_{\mathrm{e}}$. The cumulative amount of unconjugated buprenorphine and unconjugated norbuprenorphine excreted into urine was calculated from 0 to $18 \mathrm{~h}\left(A_{\mathrm{e}}\right)$, and the renal clearance $\left(\mathrm{Cl}_{\text {renal }}\right)$ using the equation $=A_{\mathrm{e}} / \mathrm{AUC}_{0-18}$. All pharmacokinetic parameters were normalized for a buprenorphine dose of $1.0 \mathrm{mg}$.

\section{Statistical analysis}

The $\mathrm{AUC}_{0-18}$ of buprenorphine was the primary outcome variable in the study, and all other pharmacokinetic and all pharmacodynamic parameters were secondary variables. Geometric mean ratios with $90 \%$ CIs were calculated for the pharmacokinetic variables. Lack of interaction was assumed if the $90 \% \mathrm{CI}$ of the geometric mean ratios for pharmacokinetic variables were within the acceptance limit of $0.8-1.25$. Pharmacokinetic variables and pharmacological effects were compared with paired Student's $t$ test. The values for $t_{\max }$ were compared by the use of Wilcoxon signed rank test. The statistical significance level was $P<0.05$. The Pearson product moment correlation coefficient was used to investigate the possible relationship between the ratios of the $\mathrm{AUC}_{0-18}$ of buprenorphine during the treatment phase (voriconazole) to the $\mathrm{AUC}_{0-18}$ of buprenorphine during the control phase, as well as to the $C_{\text {trough }}$ of voriconazole before the administration of buprenorphine. The associations of plasma buprenorphine concentrations with psychomotor and analgesic effects were also calculated using the Pearson's product moment correlation coefficient. The results are expressed as mean values and variation in data set is expressed as standard deviation (SD). $R$ software (version 3.2.0) and ggplot2 (version 2.1.0) were applied for statistical analysis and graphical presentation.

\section{Results}

Voriconazole affected strongly on the pharmacokinetics of orally administered buprenorphine and increased its effects (Fig. 1; Supplementary Figs. 1 and 2; Table 1; Supplementary Tables 1 and 2).

\section{Buprenorphine}

Compared to placebo phase, voriconazole increased the mean AUC $_{0-18}$ of oral buprenorphine 4.3-fold $(90 \%$ CI 2.7, 6.7 $P<0.001)$ and its $C_{\max } 3.9$-fold $(90 \%$ CI 2.6, 5.9; $P<0.001$ ) (Table 1; Supplementary Fig. 2). Voriconazole had no significant effect on the $t_{\max }$, but it slightly prolonged the $t_{1 / 2}$ of buprenorphine ( $P=0.042$ ). Voriconazole increased the amount of unconjugated buprenorphine excreted in urine 


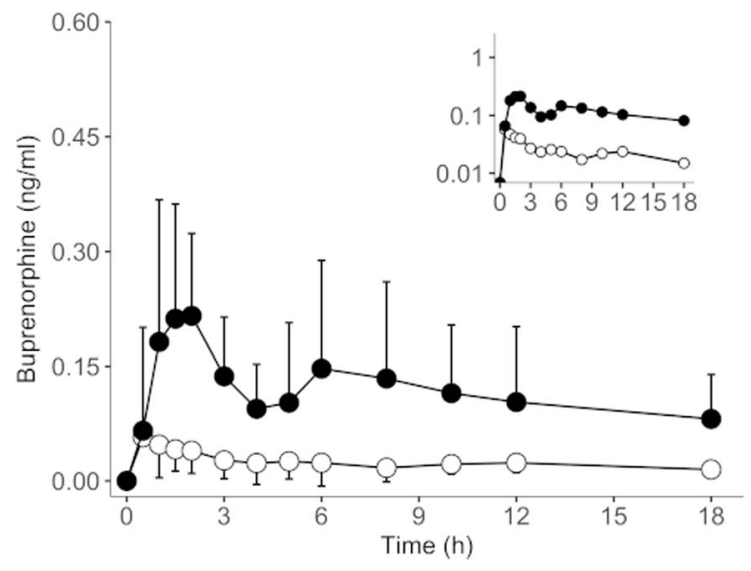

Fig. 1 Mean (SD) plasma concentrations of buprenorphine and norbuprenorphine in 12 healthy subjects after $3.6 \mathrm{mg}$ (placebo phase) or $0.2 \mathrm{mg}$ (voriconazole phase) of oral buprenorphine on the fifth day of pretreatment with placebo (empty circle) or voriconazole (filled circle)

( $P<0.001$; Supplementary Fig. 1$)$ but had no significant effect on its $\mathrm{Cl}_{\text {renal. }}$. The $A_{\mathrm{e}}$ of unchanged (unconjugated) buprenorphine was less than $0.1 \%$ of the dose during $18 \mathrm{~h}$ even during the voriconazole phase.

\section{Norbuprenorphine}

Voriconazole increased the mean $\mathrm{AUC}_{0-18}$ of norbuprenorphine nearly 4-fold (90\% CI 3.0, 5.3; $P<0.001$ ) and its $C_{\max } 3.3$-fold (90\% CI 2.4, 4.4; $P<0.001)$ compared to placebo phase (Table 1). The metabolite to the parent drug ratio $\left(\mathrm{AUC}_{\mathrm{m}} /\right.$

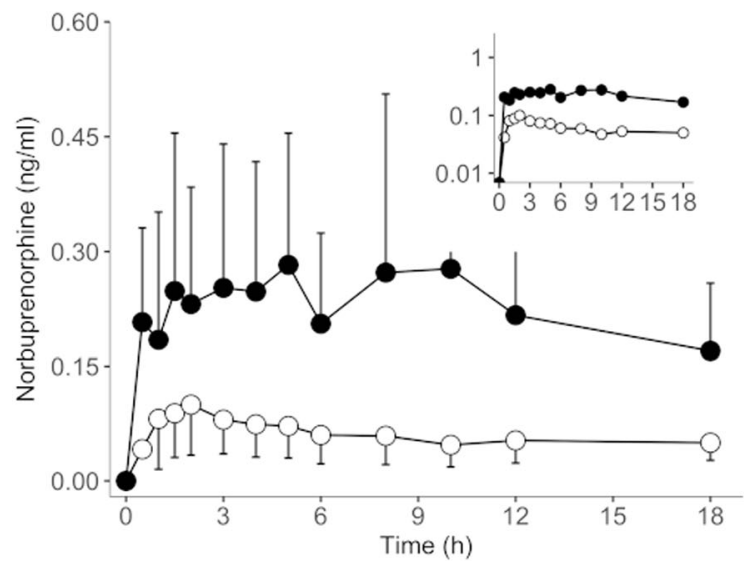

$400 \mathrm{mg}$ twice on day 1 and $200 \mathrm{mg}$ twice on days $2-5$. Concentrations are shown both on an arithmetic and a semilogarithmic scale (inset). Values are normalized for an oral dose of $1.0 \mathrm{mg}$

$\mathrm{AUC}_{\mathrm{p}}$ ) was not changed by voriconazole. Voriconazole enhanced the $A_{\mathrm{e}}$ of unconjugated norbuprenorphine by only 1.5fold $(P=0.029)$, and accordingly, voriconazole significantly $(P<0.001)$ reduced its $\mathrm{Cl}_{\text {renal }}$ (Supplementary Fig. 2).

\section{Voriconazole}

The mean (SD) plasma concentration of voriconazole $\left(C_{\text {trough }}\right)$ was 1022 (1509) $\mathrm{ng} / \mathrm{ml}$ before the administration of buprenorphine during the voriconazole phase, and the concentrations ranged from 170 to $5715 \mathrm{ng} / \mathrm{ml}$.
Table 1 Pharmacokinetic parameters of buprenorphine and norbuprenorphine after oral administration of $3.6 \mathrm{mg}$ (placebo phase) or $0.2 \mathrm{mg}$ (voriconazole phase) buprenorphine on the fifth day of pretreatment with voriconazole (400 $\mathrm{mg}$ twice on day $1,200 \mathrm{mg}$ twice on days 2-5) or placebo in 12 healthy subjects

\begin{tabular}{|c|c|c|c|c|}
\hline Parameter & Placebo & Voriconazole & $P$ value & $\begin{array}{l}\text { Geometric mean ratio } \\
(90 \% \mathrm{CI})\end{array}$ \\
\hline \multicolumn{5}{|l|}{ Buprenorphine } \\
\hline$C_{\max }(\mathrm{ng} / \mathrm{ml})$ & $0.057 \pm 0.031$ & $0.22 \pm 0.23$ & $<0.001$ & $3.87(2.55,5.88)$ \\
\hline$t_{\max }(\mathrm{h})$ & $0.5(0.5-18)$ & $2(0.5-10)$ & 0.06 & - \\
\hline $\mathrm{AUC}_{0-18}(\mathrm{ng} \mathrm{h} / \mathrm{ml})$ & $0.43 \pm 0.26$ & $2.1 \pm 1.4$ & $<0.001$ & $4.27(2.71,6.73)$ \\
\hline$t_{1 / 2}(\mathrm{~h})$ & $9.1 \pm 2.4$ & $14.5 \pm 6.8$ & 0.042 & $1.43(1.08,1.89)$ \\
\hline$A_{\mathrm{e}}(\mu \mathrm{g})$ & $0.10 \pm 0.063$ & $0.53 \pm 0.29$ & $<0.001$ & $6.76(4.68,8.83)$ \\
\hline $\mathrm{CL}_{\text {renal }}(1 / \mathrm{h})$ & $0.31 \pm 0.23$ & $0.73 \pm 1.3$ & 0.206 & $0.51(0.053,4.89)$ \\
\hline \multicolumn{5}{|l|}{ Norbuprenorphine } \\
\hline$C_{\max }(\mathrm{ng} / \mathrm{ml})$ & $0.11 \pm 0.025$ & $0.28 \pm 0.26$ & $<0.001$ & $3.29(2.44,4.43)$ \\
\hline$t_{\max }(\mathrm{h})$ & $2(0.5-12)$ & $5(0.5-8)$ & 0.35 & - \\
\hline $\mathrm{AUC}_{0-18}(\mathrm{ng} \mathrm{h} / \mathrm{ml})$ & $1.07 \pm 0.58$ & $4.0 \pm 2.1$ & $<0.001$ & $3.95(2.97,5.26)$ \\
\hline$t_{1 / 2}(\mathrm{~h})$ & $13.1 \pm 9.06$ & $17.8 \pm 7.9$ & 0.12 & $1.52(0.98,2.38)$ \\
\hline $\mathrm{AUC}_{\mathrm{m}} / \mathrm{AUC}_{\mathrm{p}}$ & $3.0 \pm 1.5$ & $3.8 \pm 5.8$ & 0.78 & $0.92(0.57,1.51)$ \\
\hline$A_{e}(\mu \mathrm{g})$ & $6.9 \pm 3.3$ & $11.6 \pm 7.8$ & 0.029 & $1.54(1.20,1.98)$ \\
\hline $\mathrm{CL}_{\text {renal }}(\mathrm{L} / \mathrm{h})$ & $7.2 \pm 2.7$ & $2.9 \pm 1.2$ & $<0.001$ & $0.39(0.29,0.52)$ \\
\hline
\end{tabular}

Values are normalized for an oral dose of $1.0 \mathrm{mg}$. Data are shown as mean \pm standard deviation (SD) and as the geometric mean ratios with the $90 \%$ confidence interval (CI) in parenthesis - except for $t_{\max }$, which is given as median and range

$C I$ confidence interval, $C_{\max }$ peak plasma concentration, $t_{\max }$ concentration peak time, $A U C_{0-18}$ area under curve from 0 to $18 \mathrm{~h}, t_{1 / 2}$ elimination half-life, $A_{e}$ amount excreted into urine within $18 \mathrm{~h}, C L_{\text {renal }}$ renal clearance 


\section{Pharmacological effects and adverse effects}

Buprenorphine caused moderate pharmacological effects (Supplementary Table 1), but their relevant comparison between the study phases is not possible due to different buprenorphine doses. The most common adverse effects were mild dizziness and nausea (Supplementary Table 2). There were no severe adverse effects, and tropisetron, naloxone, or any other rescue medication was not needed.

\section{Discussion}

We investigated the effect of voriconazole on buprenorphine pharmacokinetics when buprenorphine was swallowed immediately after its oral administration. Although oral ingestion is not commonly used in clinical practice with buprenorphine, a considerable part of the sublingual buprenorphine dose is usually swallowed and therefore susceptible to first-pass metabolism. Furthermore, in some deliberate overdoses, subjects can swallow buprenorphine concomitantly with other drugs, which could inhibit buprenorphine metabolism and increase respiratory depression. Our major finding was that voriconazole greatly increases the exposure to both parent buprenorphine and its active metabolite, norbuprenorphine, in some subjects even 6-fold. On average, voriconazole increased the AUC of oral buprenorphine two to three times more than what we observed in a previous study using sublingual administration [12].

There are only few previous studies characterizing the interactions between buprenorphine and drugs which affect its pharmacokinetics. Most of these studies have focused on high-dose sublingual buprenorphine substitution therapy. Atazanavir alone and with ritonavir increased the AUC of buprenorphine and norbuprenorphine nearly 2 -fold and lead to an increased sedative effect [25]. Darunavir-ritonavir or fosamprenavir-ritonavir combinations did not cause significant changes in plasma buprenorphine or norbuprenorphine levels [35]. Boceprevir increased plasma buprenorphine concentrations slightly but decreased norbuprenorphine concentration in plasma [36]. Similarly, lopinavir-ritonavir did not affect buprenorphine pharmacokinetics but did increase the clearance of norbuprenorphine [37]. We showed, recently, that voriconazole and posaconazole increase exposure to sublingual buprenorphine [12]. Rifampicin decreased the exposure to sublingual but not to intravenous buprenorphine [32]. These results seem to emphasize the significant role of CYP3A-mediated first-pass metabolism of buprenorphine, which sublingual administration only partially bypasses.

The metabolic fate of buprenorphine is complicated, and all its details are still not fully elucidated. Buprenorphine is extensively $\mathrm{N}$-dealkylated to norbuprenorphine, mainly by CYP3A4 [16, 17] and to some extent by CYP2C8 [18].
Also, minor CYP3A4- and CYP2C8-catalyzed buprenorphine hydroxylation pathways have been identified [18, 19, 38]. Voriconazole is a potent $\left(K_{\mathrm{i}}\right.$ values $\left.<<10 \mu \mathrm{M}\right)$ reversible inhibitor of CYP2B6, CYP2C9, CYP2C19, and CYP3A enzymes [28]. The $K_{\mathrm{i}}$ of voriconazole as a reversible inhibitor of the CYP3A4-dependent formation of norbuprenorphine has been estimated to be $5.91 \mu \mathrm{M}$ [38]. In the present study, the average plasma trough concentrations of voriconazole were around $3 \mu \mathrm{M}$, which suggests a marked inhibition potential for CYP3A4 during the whole 12-h dosing interval. The effects of voriconazole on parent buprenorphine can be mainly explained by inhibition of CYP3A4 during the firstpass and elimination phases. However, the substantial increases in the AUC and $C_{\max }$ of norbuprenorphine suggest the presence of additional mechanisms because inhibition of CYP3A4 should decrease the N-dealkylation of buprenorphine to norbuprenorphine.

Buprenorphine and norbuprenorphine are also glucuronidated. UGT2B7 accounts for more than $40 \%$ of buprenorphine glucuronidation, while norbuprenorphine glucuronidation is predominantly mediated by UGT1A3 [21]. Buprenorphine and norbuprenorphine are excreted in bile as their glucuronides, but hydrolysis to unconjugated forms by colonic bacterial beta-glucuronidases allows their reabsorption and enterohepatic circulation. Feces contain buprenorphine and norbuprenorphine predominantly in unconjugated form; in urine, they are mainly in conjugated form [5]. Effects of voriconazole and its metabolites on different UGTs and glucuronidases are not known. However, according to a semiphysiological population pharmacokinetic model, voriconazole emerges as an UGT2B inhibitor in the gut and liver [39].

Voriconazole reduced the $\mathrm{Cl}_{\text {renal }}$ of norbuprenorphine but not that of buprenorphine. Previously, voriconazole has been shown to decrease the $\mathrm{Cl}_{\text {renal }}$ of diclofenac [40]. Reduction of $\mathrm{Cl}_{\text {renal }}$ values can be explained by inhibition of membrane transporters as norbuprenorphine, but not buprenorphine, is a substrate of the efflux transporter P-glycoprotein [20]. Because the urinary excretion of (unconjugated) norbuprenorphine was very small, reduction of its $\mathrm{Cl}_{\text {renal }}$ cannot alone explain its high plasma concentrations. However, voriconazole (or its metabolites) may have affected transporters also in extrarenal tissues, and these effects may have influenced the tissue distribution of norbuprenorphine. Pglycoprotein is a major determinant of norbuprenorphine brain exposure [20], whereas buprenorphine as a lipophilic compound rapidly penetrates cell membranes without transporters. P-glycoprotein can be found in the intestinal wall, blood-brain barrier and many other tissues [41]. Thus, inhibition of P-glycoprotein and/or other transporters could influence, e.g., enterohepatic circulation and tissue concentrations of norbuprenorphine. Of note, norbuprenorphine does not have a ceiling effect on respiratory depression, and respiratory 
toxicity of buprenorphine can result from the blockade of Pglycoprotein-mediated efflux of norbuprenorphine at the blood-brain barrier [42]. Further studies are needed on the effect of drug interactions on norbuprenorphine tissue distribution and buprenorphine toxicity, keeping in mind also "opioid toxicity epidemic" [43].

In the present study, relevant comparison of pharmacological effects between the two phases was not possible because of different buprenorphine doses. We used only relatively small doses to minimize the risk of adverse events in healthy volunteers. The dose during the placebo phase (3.6 mg vs. $0.2 \mathrm{mg}$ ) was set higher, because we assumed a low oral bioavailability after immediate ingestion of the tablet. On the contrary, we wanted to keep the dose in the voriconazole phase smaller, because of the possibility of strong inhibition of buprenorphine metabolism. We based this assumption on the previous results which have established that voriconazole, and other CYP3A4 inhibitors can dramatically increase exposure to drugs that are metabolized via CYP3A4 [44-51]. We assumed dose linearity since recent reports have demonstrated that buprenorphine shows a linear increase in the exposure across a wide dose range from 0.060 to $12 \mathrm{mg}$ $[52,53]$.

We acknowledge that our study has limitations which include that it was designed mainly to evaluate the pharmacokinetics of buprenorphine. For this goal, we normalized the pharmacokinetic values to an oral buprenorphine dose of $1 \mathrm{mg}$. This made doze normalization challenging in pharmacodynamical calculations and in estimating subjective adverse effects. However, dose normalization cannot be used for pharmacodynamical results and subjective adverse effects. We drew blood samples for $18 \mathrm{~h}$, and longer sampling time might have increased the reliability in the pharmacokinetic calculations, especially in determining the elimination halflife. Therefore, the values of elimination half-life and renal clearance should be interpreted with these limitations in mind. The strengths of our study were the two-phase cross-over design and the controlled conditions that confirmed the compliance to blood sampling and urine collection. Using current study design, we could also avoid a possible pharmacokinetic interference caused by naloxone on the interaction between buprenorphine and voriconazole.

In conclusion, our results show that clinically used doses of voriconazole greatly increase the exposure to oral buprenorphine. Although oral buprenorphine is not commonly used in clinical settings, strong inhibition of its first-pass metabolism should be taken into account also when voriconazole or other potent CYP3A4 inhibitors are prescribed to patients receiving sublingual buprenorphine. Patients should be well informed and familiarized with sublingual dosing, as some part of the dose is easily ingested and swallowed. Further studies are warranted on the effect of transporter inhibitors on norbuprenorphine pharmacokinetics and pharmacodynamics because its high concentrations could increase buprenorphine toxicity.

Acknowledgements We thank Mrs. Elina Kahra (medical laboratory technologist, Clinical Pharmacology, TYKSLAB, Hospital District of Southwest Finland, Turku, Finland) for her skillful technical assistance.

Authors' contributions Mari Fihlman took care of the clinical phase of the study and data collection, participated in data analysis and statistical analysis, and wrote the manuscript. Klaus Olkkola and Kari Laine designed the study, wrote the protocol, supervised and coordinated the clinical implementation of the study, and participated in data analysis and manuscript preparation. Tuija Hemmilä participated the clinical phase and data collection. Janne T. Backman, Jouko Laitila, and Pertti J Neuvonen performed the analytical assays and participated in manuscript preparation. Teijo Saari analyzed the data, performed statistical analysis, and wrote the manuscript. All authors materially participated in the research and/or manuscript preparation. All authors have contributed to and approved the final manuscript.

Funding information

This study was supported financially by Turku University Hospital research fund (EVO 13821), Turku, Finland.

\section{Compliance with ethical standards}

The study protocol was approved by the ethics committee of the Hospital District of Southwest Finland and by the Finnish National Agency for Medicines and was registered in the EudraCT clinical trials register under code 2011-001939-23.

Conflict of interest The authors declare that they have no conflict of interest.

\section{References}

1. Dum JE, Herz A (1981) In vivo receptor binding of the opiate partial agonist, buprenorphine, correlated with its agonistic and antagonistic actions. Br J Pharmacol 74:627-633

2. Leander JD (1987) Buprenorphine has potent kappa opioid receptor antagonist activity. Neuropharmacology 26:1445-1147

3. Mattick RP, Ali R, White JM, O'Brien S, Wolk S, Danz C (2003) Buprenorphine versus methadone maintenance therapy: a randomized double-blind trial with 405 opioid-dependent patients. Addiction 98:441-452

4. Walsh SL, Preston KL, Stitzer ML, Cone EJ, Bigelow GE (1994) Clinical pharmacology of buprenorphine: ceiling effects at high doses. Clin Pharmacol Ther 55:569-580

5. Cone EJ, Gorodetzky CW, Yousefnejad D, Buchwald WF, Johnson RE (1984) The metabolism and excretion of buprenorphine in humans. Drug Metab Disp 12:577-581

6. Elkader A, Sproule B (2005) Buprenorphine: clinical pharmacokinetics in the treatment of opioid dependence. Clin Pharmacokinet 44:661-680

7. Mendelson J, Upton RA, Everhart ET, Jacob P 3rd, Jones RT (1997a) Bioavailability of sublingual buprenorphine. J Clin Pharmacol 37:31-37

8. Nath RP, Upton RA, Everhart ET, Cheung P, Shwonek P, Jones RT, Mendelson JE (1999) Buprenorphine pharmacokinetics: relative bioavailability of sublingual tablet and liquid formulations. J Clin Pharmacol 39:619-623 
9. McAleer SD, Mills RJ, Polack T, Hussain T, Rolan PE, Gibbs AD, Mullins FG, Hussein Z (2003) Pharmacokinetics of high-dose buprenorphine following single administration of sublingual tablet formulations in opioid naïve healthy male volunteers under a naltrexone block. Drug Alcohol Depend 72:75-83

10. Ciraulo DA, Hitzemann RJ, Somoza E, Knapp CM, Rotrosen J, Sarid-Segal O, Ciraulo AM, Greenblatt DJ, Chiang CN (2006) Pharmacokinetics and pharmacodynamics of multiple sublingual buprenorphine tablets in dose-escalation trials. J Clin Pharmacol 46:179-192

11. Bullingham RE, McQuay HJ, Moore A, Bennett MR (1980) Buprenorphine kinetics. Clin Pharmacol Ther 28:667-672

12. Fihlman M, Hemmilä T, Hagelberg NM, Kuusniemi K, Backman JT, Laitila J, Laine K, Neuvonen PJ, Olkkola KT, Saari TI (2016) Voriconazole more likely than posaconazole increases plasma exposure to sublingual buprenorphine causing a risk of a clinically important interaction. Eur J Clin Pharmacol 72:1363-1371

13. Kharasch ED, Hoffer C, Whittington D, Sheffels P (2003) Role of P-glycoprotein in the intestinal absorption and clinical effects of morphine. Clin Pharmacol Ther 74:543-554

14. Drewe J, Ball HA, Beglinger C, Peng B, Kemmler A, Schächinger H, Haefeli WE (2000) Effect of P-glycoprotein modulation on the clinical pharmacokinetics and adverse effects of morphine. Br J Clin Pharmacol 50:237-246

15. Dagenais C, Graff CL, Pollack GM (2004) Variable modulation of opioid brain uptake by P-glycoprotein in mice. Biochem Pharmacol 67:269-276

16. Iribarne C, Picart D, Dréano Y, Bail JP, Berthou F (1997) Involvement of cytochrome P450 3A4 in N-dealkylation of buprenorphine in human liver microsomes. Life Sci 60:1953-1964

17. Kobayashi K, Yamamoto T, Chiba K, Tani M, Shimada N, Ishizaki T, Kuroiwa Y (1998) Human buprenorphine N-dealkylation is catalyzed by cytochrome P450 3A4. Drug Metab Dispos 26:818-821

18. Moody DE, Slawson MH, Strain EC, Laycock JD, Spanbauer AC, Foltz RL (2002) A liquid chromatographic-electrospray ionizationtandem mass spectrometric method for determination of buprenorphine, its metabolite, norbuprenorphine, and a coformulant, naloxone, that is suitable for in vivo and in vitro metabolism studies. Anal Biochem 306:31-39

19. Picard N, Cresteil T, Djebli N, Marquet P (2005) In vitro metabolism study of buprenorphine: evidence for new metabolic pathways. Drug Metab Dispos 33:689-695

20. Brown SM, Holtzman M, Kim T, Kharasch ED (2011) Buprenorphine metabolites, buprenorphine-3-glucuronide and norbuprenorphine-3-glucuronide, are biologically active. Anesthesiology 115:1251-1260

21. Rouguieg K, Picard N, Sauvage FL, Gaulier JM, Marquet P (2010) Contribution of the different UDP-glucuronosyltransferase (UGT) isoforms to buprenorphine and norbuprenorphine metabolism and relationship with the main UGT polymorphisms in a bank of human liver microsomes. Drug Metab Dispos 38:40-45

22. Cone EJ, Gorodetzky CW, Yousefnejad D, Darwin WD (1985) $63 \mathrm{Ni}$ electron-capture gas chromatographic assay for buprenorphine and metabolites in human urine and feces. $\mathrm{J}$ Chromatogr 337:291-300

23. Brewster D, Humphrey MJ, Mcleavy MA (1981) Biliary excretion, metabolism and enterohepatic circulation of buprenorphine. Xenobiotica 11:189-196

24. Kapil RP, Cipriano A, Michels GH, Perrino P, O'Keefe SA, Shet MS, Colucci SV, Noveck RJ, Harris SC (2012) Effect of ketoconazole on the pharmacokinetic profile of buprenorphine following administration of a once-weekly buprenorphine transdermal system. Clin Drug Investig 32:583-592

25. McCance-Katz EF, Moody DE, Morse GD, Ma Q, DiFrancesco R, Friedland G, Pade P, Rainey PM (2007) Interaction between buprenorphine and atazanavir or atazanavir/ritonavir. Drug Alcohol Depend 91:269-278

26. Murayama N, Imai N, Nakane T, Shimizu M, Yamazaki H (2007) Roles of CYP3A4 and CYP2C19 in methyl hydroxylated and Noxidized metabolite formation from voriconazole, a new anti-fungal agent, in human liver microsomes. Biochem Pharmacol 73:2020-2026

27. Niwa T, Shiraga T, Takagi A (2005) Effect of antifungal drugs on cytochrome P450 (CYP) 2C9, CYP2C19, and CYP3A4 activities in human liver microsomes. Biol Pharm Bull 28:1805-1808

28. Jeong S, Nguyen PD, Desta Z (2009) Comprehensive in vitro analysis of voriconazole inhibition of eight cytochrome P450 (CYP) enzymes: major effect on CYPs 2B6, 2C9, 2C19, and 3A. Antimicrob Agents Chemother 53:541-551

29. Fudala PJ, Bridge TP, Herbert S, Williford WO, Chiang CN, Jones K, Collins J, Raisch D, Casadonte P, Goldsmith RJ, Ling W, Malkerneker U, McNicholas L, Renner J, Stine S, Tusel D, Buprenorphine/Naloxone Collaborative Study Group (2003) Office-based treatment of opiate addiction with a sublingual-tablet formulation of buprenorphine and naloxone. N Engl JMed 349: 949-958

30. Johnson RE, Chutuape MA, Strain EC, Walsh SL, Stitzer ML, Bigelow GE (2000) A comparison of levomethadyl acetate, buprenorphine, and METH for opioid dependence. N Engl J Med 343:1290-1297

31. Das NG, Das SK (2004) Development of mucoadhesive dosage forms of buprenorphine for sublingual drug delivery. Drug Deliv 11:89-95

32. Hagelberg NM, Fihlman M, Hemmilä T, Backman JT, Laitila J, Neuvonen PJ, Laine K, Olkkola KT, Saari TI (2006) Rifampicin decreases exposure to sublingual buprenorphine in healthy subjects. Pharmacol Res Perspect 4(6):e00271

33. Michna E, Ross EL, Hynes WL, Nedeljkovic SS, Soumekh S, Janfaza D, Palombi D, Jamison RN (2004) Predicting aberrant drug behavior in patients treated for chronic pain. J Pain Symptom Manag 28:250-258

34. Chhun S, Rey E, Tran A, Lortholary O, Pons G, Jullien V (2007) Simultaneous quantification of voriconazole and posaconazole in human plasma by high-performance liquid chromatography with ultra-violet detection. J Chromatogr B, Analyt Technol Biomed Life Sci 852:223-228

35. Gruber VA, Rainey PM, Moody DE, Morse GD, Ma Q, Prathikanti S, Pade PA, Alvanzo AA, McCance-Katz EF (2012) Interactions between buprenorphine and the protease inhibitors darunavirritonavir and fosamprenavir-ritonavir. Clin Infect Dis 54:414-423

36. Hulskotte EG, Bruce RD, Feng HP, Webster LR, Xuan F, Lin WH, O'Mara E, Wagner JA, Butterton JR (2015) Pharmacokinetic interaction between HCV protease inhibitor boceprevir and methadone or buprenorphine in subjects on stable maintenance therapy. Eur J Clin Pharmacol 71:303-311

37. Bruce RD, Altice FL, Moody DE, Morse GD, Andrews L, Lin SN, Fang WB, Ma Q, Friedland GH (2010) Pharmacokinetic interactions between buprenorphine/naloxone and once-daily lopinavir/ritonavir. J Acquir Immune Defic Syndr 54:511-514

38. Moody DE, Liu F, Fang WB (2015) Azole antifungal inhibition of buprenorphine, methadone and oxycodone in vitro metabolism. J Anal Toxicol 39:374-386

39. Frechen S, Junge L, Saari TI, Suleiman AA, Rokitta D, Neuvonen PJ, Olkkola KT, Fuhr UA (2013) Semiphysiological population pharmacokinetic model for dynamic inhibition of liver and gut wall cytochrome P450 3A by voriconazole. Clin Pharmacokinet 52:763-781

40. Hynninen VV, Olkkola KT, Leino K, Lundgren S, Neuvonen PJ, Rane A, Valtonen M, Laine K (2007) Effect of voriconazole on the pharmacokinetics of diclofenac. Fundam Clin Pharmacol 21:651-656

41. DuBuske LM (2005) The role of P-glycoprotein and organic aniontransporting polypeptides in drug interactions. Drug Saf 28:789-801 
42. Alhaddad H, Cisternino S, Declèves X, Tournier N, Schlatter J, Chiadmi F, Risède P, Smirnova M, Besengez C, Scherrmann JM, Baud FJ, Mégarbane B (2012) Respiratory toxicity of buprenorphine results from the blockage of P-glycoproteinmediated efflux of norbuprenorphine at the blood-brain barrier in mice. Crit Care Med 40:3215-3223

43. Soelberg CD, Brown RE Jr, Du Vivier D, Meyer JE, Ramachandran BK (2017) The US opioid crisis: current federal and state legal issues. Anesth Analg 125:1675-1681

44. Saari TI, Laine K, Leino K, Valtonen M, Neuvonen PJ, Olkkola KT (2006) Effect of voriconazole on the pharmacokinetics and pharmacodynamics of intravenous and oral midazolam. Clin Pharmacol Ther 79:362-370

45. Hagelberg NM, Nieminen TH, Saari TI, Neuvonen M, Neuvonen PJ, Laine K, Olkkola KT (2009) Voriconazole drastically increases exposure to oral oxycodone. Eur J Clin Pharmacol 65:263-271

46. Olkkola KT, Ahonen J, Neuvonen PJ (1996) The effects of the systemic antimycotics, itraconazole and fluconazole, on the pharmacokinetics and pharmacodynamics of intravenous and oral midazolam. Anesth Analg 82:511-516

47. Kaukonen KM, Olkkola KT, Neuvonen PJ (1997) Itraconazole increases plasma concentrations of quinidine. Clin Pharmacol Ther 62:510-517
48. Varhe A, Olkkola KT, Neuvonen PJ (1994) Oral triazolam is potentially hazardous to patients receiving systemic antimycotics ketoconazole or itraconazole. Clin Pharmacol Ther 56:601-607

49. Backman JT, Kivistö KT, Olkkola KT, Neuvonen PJ (1998) The area under the plasma concentration-time curve for oral midazolam is 400 -fold larger during treatment with itraconazole than with rifampicin. Eur J Clin Pharmacol 5453-5458, 54, 53

50. Granfors MT, Backman JT, Neuvonen M, Ahonen J, Neuvonen PJ (2004) Fluvoxamine drastically increases concentrations and effects of tizanidine: a potentially hazardous interaction. Clin Pharmacol Ther 75:331-341

51. Saari TI, Grönlund J, Hagelberg NM, Neuvonen M, Laine K, Neuvonen PJ, Olkkola KT (2010) Effects of itraconazole on the pharmacokinetics and pharmacodynamics of intravenously and orally administered oxycodone. Eur J Clin Pharmacol 66:387-397

52. Huestis MA, Cone EJ, Pirnay SO, Umbricht A, Preston KL (2013) Intravenous buprenorphine and norbuprenorphine pharmacokinetics in humans. Drug Alcohol Depend 131:258-262

53. Bai SA, Xiang Q, Finn A (2016) Evaluation of the pharmacokinetics of single- and multiple-dose buprenorphine buccal film in healthy volunteers. Clin Ther 38:358-369 